AQUINO, L.A.; PUIATTI, M.; PEREIRA, P.R.G.; PEREIRA, F.H.F.; LADEIRA, I.R.; CASTRO, M.R.S. Efeito de espaçamentos e doses de nitrogênio sobre as características qualitativas da produção do repolho. Horticultura Brasileira, Brasília, v.23, n.1, p.100-104, jan.-mar. 2005.

\title{
Efeito de espaçamentos e doses de nitrogênio sobre as características qualitativas da produção do repolho
}

\author{
Leonardo A. de Aquino; Mário Puiatti; Paulo R.G. Pereira; Francisco H.F. Pereira; Igor R. Ladeira; \\ Mariana R.S. Castro. \\ UFV, Depto. Fitotecnia, 36570-000 Viçosa-MG; E-mail: mpuiatti@ufv.br
}

\begin{abstract}
RESUMO
Avaliou-se o efeito de três espaçamentos (80x30; 60x30 e 40x30 $\mathrm{cm})$ e cinco doses de $\mathrm{N}\left(0 ; 75 ; 150 ; 225\right.$ e $\left.300 \mathrm{~kg} \mathrm{ha}^{-1}\right)$, sobre os aspectos qualitativos da produção do repolho 'Kenzan'. O experimento foi conduzido a campo, em solo com baixo teor de $\mathrm{N}$ sob delineamento inteiramente casualizado, esquema de parcelas subdivididas, com o fator espaçamento nas parcelas e doses de $\mathrm{N}$ nas subparcelas. O N foi parcelado, colocando-se $20 \%$ da dose total no transplante e aos 20 dias após o transplante (DAT) e 30\% aos 35 e aos 50 DAT. A colheita se iniciou aos 65 DAT e estendeu-se até os 83 DAT. Foram avaliadas as características: massa fresca média de cabeça; diâmetros transversal e longitudinal e volume de cabeça; teores de proteína total e de $\mathrm{NO}_{3}^{-}$na massa fresca e a perda de massa pós-colheita durante o armazenamento. Com incremento das doses de $\mathrm{N}$ observou-se aumento de valores para todas as características avaliadas, exceto para perda de massa pós-colheita, em que ocorreu o inverso. A redução do espaçamento proporcionou redução da massa fresca média, do volume, dos diâmetros transversal e longitudinal e dos teores de $\mathrm{NO}_{3}^{-}$e de proteína das cabeças, além de maior perda de massa pós-colheita. Considerando os aspectos qualitativos (formato e dimensões) da produção, o espaçamento de 40x30 cm e a dose de $253 \mathrm{~kg} \mathrm{ha}^{-1} \mathrm{de} \mathrm{N}$, seriam os mais indicados para o cultivo visando o comércio in natura. Todavia, visando-se produto destinado ao processamento o maior espaçamento, em função do maior teor protéico e da menor perda de massa fresca pós-colheita, seria o mais indicado.
\end{abstract}

Palavras-chave: Brassica oleracea var. capitata, população, nitrato, qualidade.

\begin{abstract}
Effect of spacing and doses of nitrogen on the qualitative characteristics of the yield of cabbage

The effect of three spacings $(80 \times 30 ; 60 \times 30$ and $40 \times 30 \mathrm{~cm})$ and five doses of $\mathrm{N}\left(0 ; 75 ; 150 ; 225\right.$ and $\left.300 \mathrm{~kg} \mathrm{ha}^{-1}\right)$, was evaluated on the qualitative aspects of cabbage 'Kenzan' yield. The experiment was conducted under field conditions, in soil with low nitrogen content, in a completely randomized design with split-pot scheme, and four replicates, with spacings in plot and doses in split-plot. The seedlings were produced in trays of 128 cells, under polyethylene cover greenhouse and transplanted 28 days after transplanting date (DAT). The doses of $\mathrm{N}$ were divided as follows: $20 \%$ of the total dose at transplantation and at 20 DAT and $30 \%$ at 35 and 50 DAT. Plants were harvested from 65 to 83 DAT. The average fresh head weight, transverse and longitudinal diameters, volume of head, total protein content and of $\mathrm{NO}_{3}^{-}-\mathrm{N}$ in the plant fresh weight were evaluated, besides the postharvest losses during storage. Increasing nitrogen doses caused an increment of the values of all characteristics. On the other hand, increasing nitrogen doses caused lose of the postharvest weight. A reduction of spaces resulted in smaller plant fresh weight, volume, transverse and longitudinal diameters, contents of $\mathrm{NO}_{3}^{-}-\mathrm{N}$ and protein of the heads and increased lost of mass postharvest. Considering the qualitative aspects of the production, spacing of $40 \times 30 \mathrm{~cm}$ and the dose of $253 \mathrm{~kg} \mathrm{ha}^{-1}$ of N, would be the most suitable for cabbage cultivation and in natura commercialization. When the product was destined for processing, the largest spacing would be more suitable.
\end{abstract}

Keywords: Brassica oleracea var. capitata, nitrate, population, quality.

(Recebido para publicação em 26 de março de 2004 e aceito em 27 de novembro de 2004)

$\mathrm{N}^{a}$ a agricultura moderna tem-se buscado cada vez mais maximizar os recursos disponíveis visando não somente aumento de produtividade, como outrora, mas também a busca de maior qualidade dos alimentos e a conservação do meio ambiente (Pacheco, 1996; Torres, 1999). Devido ao menor número de componentes das famílias brasileiras e do maior grau de conhecimento sobre a qualidade dos produtos, os consumidores atuais têm dado preferência a produtos de menor tamanho, quando possível, associado ao maior valor nutritivo.

Dentre as hortaliças o repolho constitui-se em alimento de excelente quali- dade, apresentando teores apreciáveis de $\beta$-caroteno, cálcio e de vitamina C (Silva Júnior et al., 1988; Ferreira et al., 2002). Um dos requisitos importante para obtenção de um produto com elevado valor nutritivo é a fertilização adequada da cultura. Sendo o repolho uma hortaliça herbácea, o $\mathrm{N}$ tende a ser o nutriente de maior influência na produtividade e qualidade, pois além de estimular o crescimento foliar, é componente de aminoácidos e de proteínas. As doses de $\mathrm{N}$ recomendadas na literatura, para a cultura do repolho, geralmente variam de 120 a $160 \mathrm{~kg} \mathrm{ha}^{-1}$ (Bora et al., 1992; Ribeiro et al., 1999; Filgueira,
2000). No entanto, estas parecem estar aquém das exigências da cultura, principalmente com o uso de cultivares mais responsivas e produtivas e da tendência crescente de se aumentar o número de plantas/área, fatores esses que podem interferir na produtividade da cultura e na qualidade do produto (Pacheco, 1996). Em repolho formas de aplicação e o parcelamento de $\mathrm{N}$ tem proporcionado produtividade até $133 \mathrm{t} \mathrm{ha}^{-1}$, todavia com massa fresca média de cabeça muito elevada, variando de 2,76 a 3,91 $\mathrm{kg}$ cabeça $^{-1}$ (Sady et al., 2001). Entretanto, os padrões de preferência do mercado consumidor brasileiro estão entre 
1,0 e $1,5 \mathrm{~kg}$ (Silva Júnior, 1988; Lédo et al., 2000).

Doses de $\mathrm{N}$ adequadas às exigências da cultura favorecem o crescimento vegetativo, o acúmulo de massa, o aumento de área foliar e, conseqüentemente, a expressão do potencial produtivo da cultura (Filgueira, 2000; Cardoso e Hiraki, 2001; Torres et al., 2003). Por outro lado, o ajuste de doses de $\mathrm{N}$ adequadas à cultura é importante para prevenção de efeitos prejudiciais à qualidade do produto, como acúmulo de nitrato $\left(\mathrm{NO}_{3}^{-}\right)$nas plantas a níveis não aceitáveis, os quais são observados quando essas são cultivadas em solos com excessiva disponibilidade do nutriente (Marschner, 1995; Torres, 1999) e que, quando em altas concentrações no organismo humano, pode formar nitrosaminas carcinogênicas além de causar a metahemoglobinemia (Pacheco, 1996; Torres, 1999). Ainda, doses elevadas de $\mathrm{N}$ podem prolongar $\mathrm{o}$ ciclo cultural, promover a redução nos teores de açúcares e de vitamina $\mathrm{C}$ e aumentar a incidência de pragas e doenças (Pacheco, 1996; Torres, 1999; Filgueira, 2000).

Menor massa fresca média das plantas com a redução do espaçamento sem, contudo, interferir na produtividade comercial tem sido observado em diversas culturas (Silva et al., 2000; Gualberto et al., 2001; Ferreira et al., 2002; Silva et al., 2003). Para o repolho, os espaçamentos comumente recomendados e/ou utilizados variam de 70$80 \mathrm{~cm}$ entre linhas e de $30-50 \mathrm{~cm}$ entre plantas (Filgueira, 2000; Lédo et al., 2000; Sady et al., 2001). A redução no espaçamento proporciona menor massa média de planta (cabeça) o que, por sua vez, pode ser benéfico, desde que a produtividade da cultura não seja reduzida, visto que melhora a qualidade estética das cabeças e sua aceitação comercial.

$\mathrm{O}$ acúmulo de $\mathrm{NO}_{3}^{-}$nas plantas, além do fator genético, também é influenciado por fatores ambientais, com destaque para intensidade de luz e a temperatura, os quais interferem no metabolismo das plantas, sobretudo do $\mathrm{N}$ (Marschner, 1995; Delistoianov, 1997). Por outro lado o espaçamento (população) interfere diretamente na captação da energia radiante que, por sua vez, irá interferir na assimilação do $\mathrm{N}$ e no acúmulo de $\mathrm{NO}_{3}^{-}$.

O presente trabalho teve por objetivo avaliar conjuntamente os efeitos de espaçamentos e de doses de $\mathrm{N}$ sobre a qualidade do repolho em cultivo de primavera.

\section{MATERIAL E MÉTODOS}

O experimento foi conduzido na horta da Universidade Federal de Viçosa, entre $23 / 09$ e 20/12/2002, utilizando-se o repolho híbrido 'Kenzan'. As mudas foram produzidas em bandejas de isopor de 128 células, sob ambiente protegido. Utilizou-se substrato agrícola comercial ('Campo Verde') enriquecido com $3 \mathrm{~kg}$ de superfosfato simples por $\mathrm{m}^{3}$ do substrato.

O solo da área experimental é classificado como Argissolo Vermelho Amarelo, cuja análise química revelou: $\mathrm{pH}$ em $\mathrm{H}_{2} \mathrm{O}=6,1$ (relação $1: 2,5$ ); $\mathrm{P}=$ $36 \mathrm{mg} \mathrm{dm}^{-3}$ e $\mathrm{K}=91 \mathrm{mg} \mathrm{dm}^{-3}(\mathrm{P}-\mathrm{K}$ : extrator Mehlich 1); $\mathrm{Ca}^{2+}=3,9 \mathrm{cmol}_{\mathrm{c}}$ $\mathrm{dm}^{-3}, \mathrm{Mg}^{2+}=0,8 \mathrm{cmol}_{\mathrm{c}} \mathrm{dm}^{-3}, \mathrm{Al}=0,0$ $\mathrm{cmol}_{\mathrm{c}} \mathrm{dm}^{-3}$, (Ca-Mg-Al: extrator $\mathrm{KCl} 1$ $\left.\mathrm{mol} \mathrm{L} \mathrm{L}^{-1}\right) ; \mathrm{H}+\mathrm{Al}=2,31 \mathrm{cmol}_{\mathrm{c}} \mathrm{dm}^{-3}$ (extrator acetato de cálcio $0,5 \mathrm{~mol} \mathrm{~L}^{-1}$, $\mathrm{pH} 7,0)$ e $\mathrm{SB}=5 \mathrm{cmol}_{\mathrm{c}} \mathrm{dm}^{-3} ; \mathrm{V}=68 \%$, $\mathrm{m}=0 \%$; e $\mathrm{M} . \mathrm{O}=19,2^{\mathrm{c}} \mathrm{g} \mathrm{kg}^{-1}$. Anteriormente à instalação do experimento, foram realizados sucessivos cultivos com milho, sem fertilização, objetivando-se reduzir os teores de $\mathrm{N}$ do solo.

Utilizou-se o delineamento experimental inteiramente casualizado, no esquema de parcelas subdivididas, com quatro repetições. As parcelas foram constituídas por três espaçamentos entre linhas $(80 ; 60$ e $40 \mathrm{~cm})$ e as subparcelas por cinco doses de $\mathrm{N}(0 ; 75$; $150 ; 225$ e $300 \mathrm{~kg} \mathrm{ha}^{-1}$ de N). A subparcela foi constituída por quatro fileiras, com oito plantas cada, espaçadas de $30 \mathrm{~cm}$, totalizando 32 plantas. Considerou-se como úteis as duas fileiras centrais, excetuando-se $60 \mathrm{~cm}$ de cada extremidade.

O preparo do solo constou de uma aração, duas gradagens e abertura manual dos sulcos de plantio com auxílio de enxada. Com exceção do N, as adubações com os demais nutrientes foram realizadas com base na análise química do solo e recomendações para a cultura do repolho para o estado de Minas Gerais (Ribeiro et al., 1999). No sulco de plantio foram aplicados: $300 \mathrm{~kg} \mathrm{ha}^{-1} \mathrm{de}$ $\mathrm{P}_{2} \mathrm{O}_{5}, 36 \mathrm{~kg} \mathrm{ha}^{-1}$ de $\mathrm{K}_{2} \mathrm{O}$ e $20 \%$ da dose total de $\mathrm{N}$ de cada tratamento, utilizando-se como fontes superfosfato simples, cloreto de potássio e uréia, respectivamente. Aplicou-se ainda, no plantio, o equivalente a $15 \mathrm{~kg} \mathrm{ha}^{-1}$ de sulfato de zinco, $10 \mathrm{~kg} \mathrm{ha}^{-1} \mathrm{de}$ bórax, $10 \mathrm{~kg} \mathrm{ha}^{-1} \mathrm{de}$ sulfato de cobre e $0,5 \mathrm{~kg} \mathrm{ha}^{-1} \mathrm{de}$ molibdato de amônio (Ribeiro et al., 1999). Todos os fertilizantes aplicados no sulco de plantio foram distribuídos e incorporados ao solo cinco dias antes do transplante das mudas. As mudas foram transplantadas para o local definitivo aos 28 dias após a semeadura, contendo 4 a 5 folhas completas. Em cobertura foram realizadas três adubações, com $\mathrm{N}$ e K, aos 20, 35 e 50 dias após o transplante (DAT) das mudas. Aos 20 DAT foram aplicados $20 \%$ da dose total de $\mathrm{N}$ e 36 $\mathrm{kg} \mathrm{ha}^{-1}$ de $\mathrm{K}_{2} \mathrm{O}$; e nas duas posteriores aplicou-se, em cada uma, $30 \%$ da dose total de $\mathrm{N}$ e $54 \mathrm{~kg} \mathrm{ha}^{-1}$ de $\mathrm{K}_{2} \mathrm{O}$.

Durante a condução do experimento realizaram-se duas capinas manuais, aos 18 e 31 DAT, para controle de plantas daninhas. Realizou-se também, aos 28 DAT, uma pulverização à base de Deltametrina para o controle da traça das brassicas (Plutella xylostella). A irrigação foi realizada por aspersão convencional, de acordo com as necessidades da cultura.

As cabeças foram colhidas à medida em que iam alcançando a compacidade desejada (firmeza à compressão manual), o que ocorreu dos 65 aos 83 DAT. Em cada subparcela foram colhidas sete plantas da área útil, uniformes e representativas do tratamento. Dessas, duas cabeças foram imersas em balde com água para medição do volume da cabeça pelo método do deslocamento d'água; duas foram secionadas longitudinalmente, para medições dos diâmetros transversal (DT) e longitudinal (DL), com auxílio de régua, das quais retirou-se uma fatia, de aproximadamente $1,5 \mathrm{~cm}$ de espessura, em toda a extensão longitudinal, para determinação dos teores de $\mathrm{NO}_{3}^{-}$e de N-orgânico. As fatias foram colocadas para secar em estufa com ventilação de ar forçada, a $65^{\circ} \mathrm{C}$ até peso constante. Após a seca- 
Tabela 1. Massa fresca média e volume médio de cabeça em função de espaçamentos dentro de doses de N na cultura do repolho. Viçosa, UFV, 2002.

\begin{tabular}{|c|c|c|c|c|c|}
\hline \multirow{2}{*}{ Espaçamentos } & \multicolumn{5}{|c|}{ Doses de N $\left(\mathrm{kg} \mathrm{ha}^{-1}\right)$} \\
\hline & 0 & 75 & 150 & 225 & 300 \\
\hline & \multicolumn{5}{|c|}{ Massa fresca média de cabeça $\left(\mathrm{g} \mathrm{cabeça}^{-1}\right)$} \\
\hline$\overline{\mathrm{E} 1(80 \times 30 \mathrm{~cm})}$ & $821,65 a$ & 1163,35 a & $1633,55 \mathrm{a}$ & $1950,00 \mathrm{a}$ & $2310,20 \mathrm{a}$ \\
\hline E2 (60X30cm) & $823,53 \mathrm{a}$ & $1243,15 a$ & 1621,03 a & 1833,93 a & $1729,15 \mathrm{~b}$ \\
\hline \multirow[t]{3}{*}{ E3 $(40 \times 30 \mathrm{~cm})$} & $375,60 \mathrm{~b}$ & $616,03 \mathrm{~b}$ & $880,83 \mathrm{~b}$ & $1237,08 \mathrm{~b}$ & 1218,35 \\
\hline & \multicolumn{5}{|l|}{ CV1= 15,96\%; } \\
\hline & \multicolumn{5}{|c|}{ Volume médio de cabeça $\left(\mathrm{cm}^{3}\right)$} \\
\hline$\overline{E 1}(80 \times 30 \mathrm{~cm})$ & $947,52 \mathrm{a}$ & 1841,26 a & 2537,00 a & 3075,08 a & 3237,58 a \\
\hline $\mathrm{E} 2(60 \times 30 \mathrm{~cm})$ & 827,50 a & 1542,50 a & $1942,51 \mathrm{~b}$ & $2962,51 \mathrm{a}$ & $2801,25 a$ \\
\hline \multirow[t]{2}{*}{ E3 $(40 \times 30 \mathrm{~cm})$} & $581,27 \mathrm{a}$ & $831,23 \mathrm{~b}$ & $1291,22 \mathrm{C}$ & $1595,03 \mathrm{~b}$ & $2081,22 b$ \\
\hline & $C V 1=13,63 \%$ & & $C V 2=18,0$ & & \\
\hline
\end{tabular}

Dentro de cada característica, médias, nas colunas, seguidas por pelo menos uma mesma letra, não diferem entre si pelo teste de Tukey a $5 \%$ de probabilidade; $C V 1=$ coeficiente de variação da parcela; CV2=coeficiente de variação da subparcela.

Tabela 2. Diâmetros transversal (DT) e longitudinal (DL), teor de nitrato (NFC), teor protéico (TPC) e perda de massa pós-colheita (PMPC) na cabeça em função de espaçamentos na cultura do repolho. Viçosa, UFV, 2002

\begin{tabular}{|c|c|c|c|c|c|}
\hline Espaçamentos & DT (cm) & $\mathrm{DL}$ (cm) & $\begin{array}{c}\mathrm{NFC} \\
\left(\mathrm{mg} \mathrm{kg}^{-1} \mathrm{MF}\right)\end{array}$ & $\begin{array}{c}\mathrm{TPC} \\
\text { (dag Kg }^{-1} \text { de } \\
\left.\mathrm{MS}^{-}\right)\end{array}$ & $\begin{array}{c}\text { PMPC } \\
\left(g^{-k^{-1}} \text { de }\right. \\
\text { MF) }\end{array}$ \\
\hline $\mathrm{E} 1(80 \times 30 \mathrm{~cm})$ & 17,11 a & $13,21 \mathrm{a}$ & $123,94 \mathrm{a}$ & $21,38 a$ & $161.745 \quad b$ \\
\hline E2 $(60 \times 30 \mathrm{~cm})$ & 15,54 a & $12,79 a b$ & $90,94 \mathrm{~b}$ & $16,75 \mathrm{~b}$ & $154.935 \mathrm{~b}$ \\
\hline E3 $(40 \times 30 \mathrm{~cm})$ & $13,02 \mathrm{~b}$ & $11,97 \quad b$ & $79,23 \quad c$ & $18,13 b$ & 209.330 a \\
\hline $\mathrm{CV}(\%)$ & 9,59 & 6,29 & 35,18 & 13,12 & 16,81 \\
\hline
\end{tabular}

Dentro de cada característica, médias, nas colunas, seguidas por pelo menos uma mesma letra, não diferem entre si pelo teste de Tukey a $5 \%$ de probabilidade.

gem as amostras foram trituradas e porções de $0,1 \mathrm{~g}$ foram pesadas para a determinação do teor de $\mathrm{NO}_{3}^{-}$(Cataldo et al., 1975). O N-orgânico foi determinado a partir de porções de $0,1 \mathrm{~g}$ (Jackson, 1958). Somou-se os valores de N-orgânico e de $\mathrm{NO}_{3}^{-}$, obtendo-se o teor de $\mathrm{N}$ total, a partir do qual estimou-se o teor protéico, multiplicando seu respectivo valor pelo fator 6,25 (Watt e Merril, 1975). As três cabeças restantes, após pesadas para obtenção da massa fresca inicial, foram armazenadas em condições ambiente de laboratório, com temperatura média de $22^{\circ} \mathrm{C}$ e UR de $84 \%$, durante uma semana, fazendo-se o acompanhamento diário da perda de massa (pesagens) pós-colheita.

Os resultados obtidos, das características avaliadas, foram submetidos às análises de variâncias utilizando-se do programa estatístico SAEG (Ribeiro Júnior, 2001). Nas análises considerouse doses de $\mathrm{N}$ como fator quantitativo, sendo feita análise de regressão, enquanto os espaçamentos foram considerados como fator qualitativo, comparando-se as médias pelo teste de Tukey a 5\% de probabilidade.

\section{RESULTADOS E DISCUSSÃO}

Houve interação espaçamentos $\mathrm{x}$ doses de $\mathrm{N}$ para massa fresca média e volume médio das cabeças (Tabela 1 e Figura 1). Para as demais características houve efeito simples de espaçamentos e de doses de N (Tabela 2 e Figura 1).

A massa fresca média de cabeça aumentou com incremento das doses de $\mathrm{N}$ (Figura 1) e diminuiu com a redução do espaçamento (Tabela 1), contudo sem prejuízo na produção de massa fresca de cabeça/área (Aquino et al., 2004). Resultados semelhantes em estudos com verificados para diversas culturas (Silespaçamentos e/ou doses de $\mathrm{N}$, foram va et al., 2000; Ferreira et al., 2002; Silva et al., 2003), e comprova a importância do ajuste do espaçamento e da dose de $\mathrm{N}$ de forma a maximizar a assimilação do $\mathrm{N}$ e o acúmulo de massa.

$\mathrm{O}$ volume médio de cabeça aumentou linearmente com o incremento das doses de N (Figura 1), sendo esse efeito mais acentuado nos espaçamentos maiores (E1 e E2), (Tabela 1). Por sua vez, os diâmetros transversal e longitudinal aumentaram de forma quadrática com o incremento das doses de N, com máximos estimados de 18,83 e 13,76 cm, obtidos com as doses de 288,6 e 215,4 $\mathrm{kg} \mathrm{ha}^{-1}$ de N, respectivamente. Tal como para o volume, esse efeito foi mais acentuado nos espaçamentos maiores (E1 e E2), (Tabela 1). Esses resultados comprovam a importância do N no crescimento das plantas de repolho, bem como a maior competição que ocorre nos menores espaçamentos. Portanto, mesmo com o aumento nas doses de N, a redução no espaçamento entre plantas proporcionou cabeças com menores massa fresca média, volume e diâmetros, que são características importantes para o mercado, cujo consumidor brasileiro prefere repolho ("cabeças") de menor tamanho. A redução da massa fresca e do volume médio de cabeça, sem decrescer a produção/área, é interessante ao produtor por permitir a obtenção de cabeças com dimensões dentro dos padrões comerciais exigidos pelo mercado e pelo consumidor (1,0 a 1,5 $\mathrm{kg}$ ) aumentando a possibilidade de comercialização.

Os teores de nitrato e de proteína na cabeça, similarmente às características de crescimento, aumentaram com o incremento nas doses de N (Figura 1) e do espaçamento (Tabela 2). Esse comportamento deveu-se à maior disponibilidade de $\mathrm{N}$ às plantas em doses mais elevadas de $\mathrm{N}$ aplicado e/ou quando há menor número de plantas/área (maiores espaçamentos). $\mathrm{O}$ acúmulo de $\mathrm{NO}_{3}^{-} \mathrm{em}$ plantas é observado quando há excesso de absorção em relação à assimilação, ou seja, incorporação do $\mathrm{N}$ em moléculas orgânicas, uma vez que, havendo $\mathrm{N}$ disponível no solo para absorção a planta tende a absorvê-lo além de sua demanda e estocá-lo nos vacúolos na forma de $\mathrm{NO}_{3}^{-}$(Marschner, 1995; 
Delistoianov, 1997). A absorção e o acúmulo de $\mathrm{NO}_{3}^{-}$depende de vários fatores como, por exemplo: intensidade luminosa, temperatura, espécie, variedade, órgão vegetal e idade do órgão considerado, além da interação com outros nutrientes. Todavia, a disponibilidade de N no solo para absorção é considerado o fator de maior importância.

Neste experimento considerando a maior dose aplicada de N (300 $\left.\mathrm{kg} \mathrm{ha}^{-1}\right)$, o teor de $\mathrm{NO}_{3}^{-}$máximo estimado foi de $181,3 \mathrm{mg} \mathrm{kg}^{-1}$ de massa fresca (MF). Este valor está aquém dos limites aceitos por países europeus, que variam de 500 a $1500 \mathrm{mg} \mathrm{kg}^{-1}$ de MF (Scharph, 1991). O teor de proteína aumentou linearmente com as doses de N, e diminuiu com a redução dos espaçamentos (Tabela 2 e Figura 1). O aumento da dose de $\mathrm{N}$ e/ou maior espaçamento promoveram maior disponibilidade de $\mathrm{N}$ às plantas, concorrendo para maior conteúdo protéico (Pacheco, 1996).

Observou-se menores perdas de massa pós-colheita com incremento das doses de N (Figura 1) e aumento do espaçamento (Tabela 2). Em espaçamentos menores ocorreu, conjuntamente, menor disponibilidade de nutrientes às plantas e maior competição por demais fatores de crescimento, entre esses a luz, o que possivelmente promoveu menor acúmulo de fotoassimilados e de minerais; menor conteúdo destes fez com que o potencial hídrico se tornasse maior, aumentando o fluxo de água das cabeças para o ambiente no armazenamento. Apesar da "cabeça" de repolho apresentar as folhas imbricadas, o que dificulta a perda d'água pelas folhas internas, outra possível explicação para a maior perda de massa, no menor espaçamento, seria a maior superfície específica (relação superfície/volume) encontrada em "cabeças" menores, uma vez que a massa fresca média, o volume de "cabeça" e diâmetros diminuíram com a redução do espaçamento (Tabelas 1 e 2). Por outro lado o incremento das doses de $\mathrm{N}$ e do espaçamento, aumentou a disponibilidade de nutrientes e de luz para as plantas, promovendo maior acúmulo de fotoassimilados e de minerais, diminuindo o potencial hídrico da cabeça promovendo assim, menor perda de água para o ambiente, além da menor superfície específica dessas cabeças.
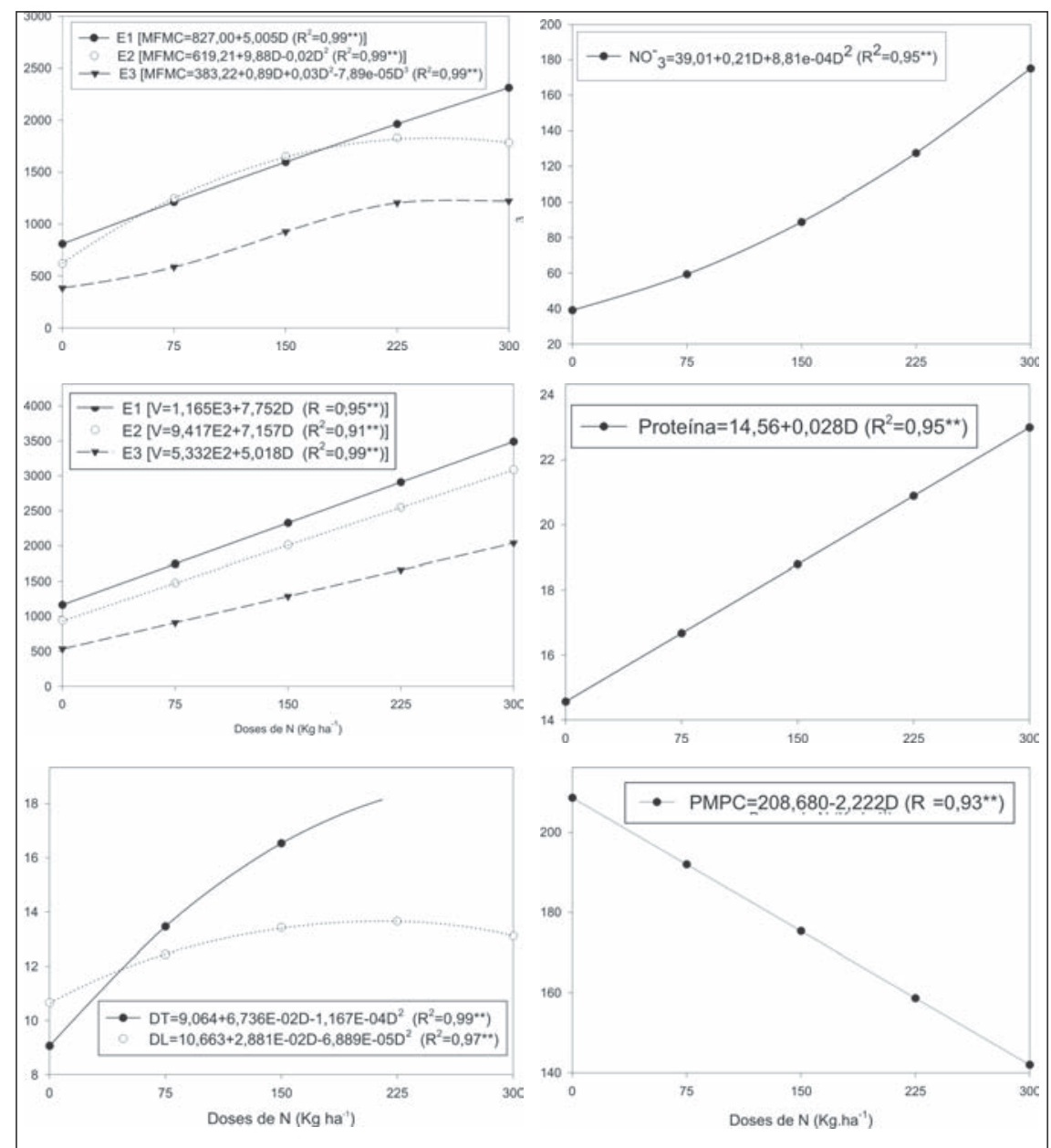

Figura 1. Massa fresca média, volume, diâmetros transversal (DT) e longitudinal (DL), teor de nitrato $\left(\mathrm{NO}_{3}^{-}\right)$e proteína e perda de massa pós-colheita da cabeça em função de espaçamentos e doses de N. Viçosa, UFV, 2002.

Considerando os aspectos qualitativos (formato e dimensões) e quantitativos (Aquino et al., 2004) da produção, o espaçamento de $40 \times 30 \mathrm{~cm}$ e a dose de $253 \mathrm{~kg} \mathrm{ha}^{-1}$ de $\mathrm{N}$, seriam os mais indicados para o cultivo de repolho na primavera visando o comércio in natura, devendo-se agilizar o processo da comercialização do produto devido à maior perda de massa pós-colheita. Todavia, visando-se produto destinado ao processamento e/ou maior período de armazenamento, sugere-se a utilização do maior espaçamento em função do maior teor protéico e da menor perda de massa fresca pós-colheita observados neste espaçamento.

\section{AGRADECIMENTOS}

Os autores agradecem ao CNPq pela bolsa de iniciação científica (IC) concedida ao primeiro autor.

\section{LITERATURA CITADA}

AQUINO, L.A.; PUIATTI, M.; PEREIRA, P.R.G.; PEREIRA, F.H.F.; CASTRO, M.R.S.; LADEIRA, I.R. Características produtivas do repolho em função de espaçamentos e doses de nitrogênio. Horticultura Brasileira, Brasília (no prelo).

BORA, G.C.; DEKA, B.C.; SHADEQUE, A. Effect of different levels of nitrogen and spacing on head yield of cabbage (Brassica oleraceae convar. capitata var. capitata). Indian Journal of Agricultural Sciences, v.62, n.8, p.527-528, 1992 CARDOSO, A.I.I.; HIRAKI, H. Avaliação de doses e épocas de aplicação de nitrato de cálcio em cobertura na cultura do rabanete. Horticultura Brasileira, Brasília, v.19, n.3, p.328-331, 2001.

CATALDO, D.A.; HAROON, M.; SCHARDER, M.; YOUNGS, V.L. Rapid colorimetric of nitrate in plant tissue by nitrification of salicylic acid. Communication Soil Science Plant Analyses, v.6, n.1, p.71-81, 1975.

DELISTOIANOV, F. Produção, teores de nitrato e capacidade de rebrota de cultivares de alface, sob estufa, em hidroponia e solo, no verão e outono. 1997. 76 f. (Tese mestrado) - UFV, Viçosa. 
FERREIRA, W.R.; RANAL, M.A.; FILGUEIRA, F.A.R. Fertilizantes e espaçamento entre plantas na produtividade da couve da malásia. Horticultura Brasileira, Brasília, v.20, n.4, p.635640, 2002.

FILGUEIRA, F.A.R. Novo Manual de Olericultura: agrotecnologia moderna na produção e comercialização de hortaliças. Viçosa: UFV, 2000. 402 p.

GUALBERTO, R.; RESENDE, F.V.; LOSASSO, P.H.L. Produtividade e qualidade do melão rendilhado em ambiente protegido, em função do espaçamento e sistema de condução. Horticultura Brasileira, Brasília, v.19, n.3, p.373-375, 2001.

JACKSON, M.L. Nitrogen determinations for soil and plants tissue. In: JACKSON, M.L. Soil chemical analysis. Engjewood Chiffis: Prentice Hall, 1958. p.183-204.

LÉDO, F.J.S.; SOUZA, J.A.; SILVA, M.R. Avaliação de cultivares e híbridos de repolho no Estado do Acre. Horticultura Brasileira, Brasília, v.18, n.2, p.138-140, 2000.

MARSCHNER, H. Mineral nutrition of higher plant. 2.ed. New York: Academic Press, 1995. 889 p.
PACHECO, D.D. Índices de disponibilidade de nitrogênio, teores de nitrato e de vitamina $C$, composição mineral e produção de repolho em resposta a doses de nitrogênio, de composto orgânico e de molibdênio. 1996. 79 f. (Tese mestrado) UFV, Viçosa.

RIBEIRO, A.C.; GUIMARÃES, P.T.G.; ALVAREZ, V.H. Recomendações para o uso de corretivos e fertilizantes em Minas Gerais: $5^{a}$ aproximação. Viçosa: Comissão de fertilidade do solo do estado de minas gerais, 1999. 359 p.

RIBEIRO JÚNIOR, I.R. Análises estatísticas no SAEG. Viçosa: UFV, 2001. 301 p.

SADY, W.; WOJCIECHOWSKA, R.; ROZEK, S. The effect of form and placement of $\mathrm{N}$ on yield and nitrate content of white cabbage. Acta Horticulture, n.563, p.123-128, 2001.

SCHARPH, H.C. Nutrient influences on the nitrate content of vegetable. The Fertilizer Society, n.313. 1991. 24 p. (Proceedings, 313)

SILVA JÚNIOR, A.A.; MIURA, L.; YOKOYAMA, S. Repolho: novas cultivares de verão. Agropecuária Catarinense, Florianópolis, v.1, n.3, p.47-49, 1988
SILVA, V.F.; NETO, F.B.; NEGREIROS, M.Z.; PEDROSA, J.F. Comportamento de cultivares de alface em diferentes espaçamentos sob temperatura e luminosidade elevadas. Horticultura Brasileira, Brasília, v.18, n.3, p.183-187, 2000.

SILVA, P.S.L.; OLIVEIRA, F.H.T.; SILVA, P.I.B. Efeitos da aplicação de doses de nitrogênio e densidades de plantio sobre os rendimentos de espigas verdes e de grãos de milho. Horticultura Brasileira, Brasília, v.21, n.3, p.452-455, 2003.

TORRES, A.N.L. Produção e qualidade de variedades de repolho e cenoura. 1999. 72 f. (Tese mestrado) - UFV, Viçosa.

TORRES, J.L.R.; FABIAN, A.J.; POCAY, V.G. Níveis de adubação nitrogenada nas características morfológicas e produtividade do jiló. Horticultura Brasileira, Brasília, v.21, n.2, p.167170, 2003.

WATT, B.K., MERRIL, A.L. Handbook of the nutrition contents of foods. New York: USA, United States Departament of Agriculture. Dover Publication, 1975. 190 p. 